\title{
Remineralizing Efficacy of Fluorohydroxyapatite Gel on Artificial Dentinal Caries Lesion
}

\author{
Qianqian Wang, ${ }^{1}$ Shize Liu, ${ }^{2}$ Xuejun Gao, ${ }^{3}$ Yan Wei, ${ }^{1}$ Xuliang Deng, ${ }^{1,4}$ \\ Haifeng Chen, ${ }^{2}$ and Xuehui Zhang ${ }^{1,5}$ \\ ${ }^{1}$ Department of Geriatric Dentistry, Peking University School and Hospital of Stomatology, Beijing 100081, China \\ ${ }^{2}$ Department of Biomedical Engineering, College of Engineering, Peking University, Beijing 100081, China \\ ${ }^{3}$ Department of Cariology and Endodontology, Peking University School and Hospital of Stomatology, Beijing 100081, China \\ ${ }^{4}$ National Engineering Laboratory for Digital and Material Technology of Stomatology, Beijing 100081, China \\ ${ }^{5}$ Department of Dental Materials, Peking University School and Hospital of Stomatology, Beijing 100081, China
}

Correspondence should be addressed to Haifeng Chen; haifeng.chen@pku.edu.cn and Xuehui Zhang; zhangxuehui914@163.com

Received 22 May 2015; Revised 20 August 2015; Accepted 20 August 2015

Academic Editor: Anh-Tuan Le

Copyright (c) 2015 Qianqian Wang et al. This is an open access article distributed under the Creative Commons Attribution License, which permits unrestricted use, distribution, and reproduction in any medium, provided the original work is properly cited.

\begin{abstract}
The aim was to evaluate the remineralizing efficacy of fluorohydroxyapatite (FHA) gel on artificial dentinal caries lesion in vitro. Artificial carious lesions were made on occlusal cavities of teeth by exposing the dentin surface to a demineralizing solution. Each cavity was capped with a $3 \mathrm{~mm}$ thick FHA gel for 4 weeks. After the FHA gel was removed, the surface morphology and structure of the dentin were characterized by scanning electron microscopy (SEM), energy-dispersive X-ray spectroscopy (EDX), X-ray diffraction (XRD), and Fourier transform infrared spectroscopy (FT-IR). The dentin mineral density (DMD) was measured by micro-computed tomography (Micro-CT). A layer of dense and orderly hexagonal crystal structure, with average diameter of $1 \mu \mathrm{m}$ and thickness of $4 \sim 5 \mu \mathrm{m}$, could be observed on dentin surface. These crystals exhibited elemental peaks for calcium, phosphorus, carbon, and oxygen and characteristic peaks of hydroxyapatite (HA) and fluorapatite (FA) via XRD and FT-IR. The DMD of dentin surface layer significantly increased after it was capped with FHA gel $(P<0.05)$. In the present study, the FHA gel could rapidly construct apatite on the artificial dentin caries surface and significantly increase the mineral density, which suggests that FHA gel might be a proper IPT material with remineralizing function.
\end{abstract}

\section{Introduction}

Minimally invasive dentistry (MID) is the application of "a systematic respect for the original tissue." This implies that the dental profession recognizes that an artifact is of less biological value than the original healthy tissue [1]. In deep caries dentin discoloration occurs far in advance of the infection by microorganisms, and as much as $2 \mathrm{~mm}$ of the softened or discolored dentin is not infected but is reversibly denatured $[2,3]$. Residual affected dentin has been suggested to be retained so as to keep its potential of being remineralized, which is otherwise removed in traditional carious excavation procedures. Indirect pulp-capping therapy (IPT) is considered as a minimally invasive treatment, in which caries are excavated and the tooth is restored with a suitable material $[1,3]$. In doing so, the caries process can be halted, and the residual affected dentin can be remineralized, which can be promoted by bioactive and ionreleasing base materials [4]. The key success factor is the application of remineralized materials during indirect pulpcapping therapy (IPT).

Over the years, calcium hydroxide $\left(\mathrm{Ca}(\mathrm{OH})_{2}\right)$ has emerged as a gold standard for IPT. The benefits of $\mathrm{Ca}(\mathrm{OH})_{2}$ include its antimicrobial and anti-inflammatory effects, low thermal conductivity, and an ability to act as a buffer against the direct restorations [5-7]. However, it is still unknown whether this kind of material could remineralize dentin beneath $\mathrm{Ca}(\mathrm{OH})_{2}$. It merely provides hydroxide and calcium ions upon dissolution, but not the phosphate ion needed during remineralization.

Another IPT material, mineral trioxide aggregate (MTA), has been found to be important in dentistry due to its 
biocompatibility and bioactive properties, which has been available since the early 1990s, displaying excellent potential in endodontic applications [8-11]. As the calcium silicatecontaining material lacks phosphate, the MTA becomes bioactive and produces apatite only when it comes into contact with phosphate-containing fluids [12]. The procedure is effective in vitro in promoting optimal remineralization of the mineral-sparse surface of a carious lesion, but it is not possible to rely on dissolving biomimetic analogs in body fluids in a clinical setting [13]. As a result, these problems are leading scientists to explore new IPT materials which possess remineralizing efficacy in addition.

A new material system, fluorohydroxyapatite (FHA) gel system, has been developed for which prism-like structures on enamel were rapidly constructed on the natural human enamel surface using this gel system which contains $\mathrm{Ca}\left(\mathrm{NO}_{3}\right)_{2}, \mathrm{KH}_{2} \mathrm{PO}_{4}$, $\mathrm{KF}$, deionized water, and agarose [14]. This reaction occurs by spontaneous mineral nucleation on the surface of etched enamel under physiological conditions. The newly grown prism-like structure on enamel is identified as fluorapatite. It is hypothesized that the FHA gel may also form apatite structures on residual affected dentin in deep caries and may promote dentin remineralization. Within these parameters, the FHA gel could be applied as a suitable IPT material. The present study aims to evaluate the remineralizing efficacy of FHA gel system on artificial dentinal caries lesions when the gel is used as an IPT material, comparing it with calcium hydroxide and MTA.

\section{Materials and Methods}

2.1. Preparation of Artificial Caries. Sixty noncaries human third molars were obtained from the Peking University School of Stomatology under an agreement with the patients. The protocol for processing human tissue specimens was reviewed and approved by the University Committee on Use and Care of Human Tissue Specimens. The root was removed from the cement-enamel junction of the tooth, and only the crown was left. A cavity measuring $5 \mathrm{~mm}$ in length and width and $6 \mathrm{~mm}$ in thickness was made on the occlusal surface of the tooth, and the bottom of the cavity was positioned on the center of the dentin layer. Each side of the specimen was then painted with an acid-resistant nail varnish except for the dentin surface of cavity walls. Artificial carious lesions were induced by exposing the dentin surface to a demineralizing solution consisting of $0.1 \mathrm{M}$ lactic acid which was adjusted to pH 5.0 for 72 hours [15]. Subsequently, the specimens were thoroughly rinsed with deionized water and 54 specimens were divided into three groups of 18 in each; the other 6 specimens were assigned to a control group.

2.2. IPT and Remineralization Experiments. The three test groups were as follows:

Group FHA: FHA gel (PCT/CN2013/001026),

Group $\mathrm{CH}: \mathrm{Ca}(\mathrm{OH})_{2}$ (Calxyl, OCO-Präparat GMBH, Dirmstein, Germany),

Group MTA: MTA (ProRoot MTA, Dentsply Tulsa, Dentsply International. Inc., USA).
FHA gel, which contained $0.40 \mathrm{M} \mathrm{Ca}\left(\mathrm{NO}_{3}\right)_{2}, \quad 0.24 \mathrm{M}$ $\mathrm{KH}_{2} \mathrm{PO}_{4}, 0.08 \mathrm{MKF}$, deionized water, and agarose, was provided by the Department of Biomedical Engineering, College of Engineering, Peking University [14]. Briefly, agarose was added to the $\mathrm{Ca}\left(\mathrm{NO}_{3}\right)_{2}$ solution and heated with a microwave oven for 5-10 seconds. By adding $\mathrm{KH}_{2} \mathrm{PO}_{4}$ and $\mathrm{KF}$ to the heated solution, the mixed solution would cure and form agarose gel in 30 minutes under physiological conditions.

$\mathrm{Ca}(\mathrm{OH})_{2}$ and MTA materials were mixed as per the manufacturers' instructions.

Each cavity was capped with $3 \mathrm{~mm}$ thick materials, respectively, and subsequently restored with composite resin. They were placed in a $5 \mathrm{~mL}$ physiological saline solution at $37^{\circ} \mathrm{C}$ for 4 weeks. After 1 or 4 weeks, specimens were removed from the solution and prepared for examination. After the restoration and the materials were carefully separated from the cavity using explorer, specimens were washed with deionized water in ultrasonic cleaner for $15 \mathrm{~min}$ at $25 \mathrm{KHz}$ (Transonic TP690, Elma, Germany).

2.3. Scanning Electron Microscopy and Elemental Analysis. The surface morphology and structure of the artificial dentin caries were characterized via a scanning electron microscopy (SEM, ZEISS, Supra 55, Germany). The elemental composition of the mineral crystal constructed on a remineralized layer was characterized by energy-dispersive X-ray spectroscopy (EDX, ZEISS, Supra 55, Germany).

2.4. X-Ray Diffraction and Fourier Transform Infrared Spectroscopy. The phase composition and structure of the mineral crystal were evaluated by X-ray diffraction spectroscopy (XRD, Rigaku D/max $2500 \mathrm{VB} 2+/ \mathrm{PC}$, Japan) at $40 \mathrm{~mA}$ and $45 \mathrm{kV}$ as well as by Fourier transform infrared spectroscopy (FT-IR, Nicolet 8700, USA). For Group FHA, XRD samples were the crystal powder scraped from the artificial caries layer. For Groups CH and MTA, XRD samples were the cured materials removed from the artificial caries cavity.

2.5. Micro-CT Scanning. The mineral density and lesion depth of artificial dentin caries were measured by the Inveon micro-computed tomography system (SIEMENS Medical Solutions, USA).

Scanning was performed with a spatial resolution of $9.21 \mu \mathrm{m}$ at $80 \mathrm{kV}$ and $500 \mu \mathrm{A}$ and $360^{\circ}$ rotation. The slab was rescanned during subsequent weeks with the same acquisition and reconstruction parameters. Following the scanning and image reconstruction, a three-dimensional (3D) image was obtained using COBRA Exxim software and analyzed via Data Analysis System (Inveon Research workplace 4.1). Mineral profiles were determined at precisely the same area $(5 \times 5 \times 0.05 \mathrm{~mm})$ within the $3 \mathrm{D}$ image during the experiment and the mineral density was acquired. Parameters of dentin mineral density (DMD) of the lesions and lesion depth were obtained in this study.

Specimens' assignments were analyzed with one-way ANOVA to ensure that there were no differences in the baseline mineral density and lesion depth among the groups. There were 18 specimens in each experimental group, 6 of 
which were examined by SEM-EDX and XRD-FTIR at 1 week and another 6 at 4 weeks. The other 6 were examined with micro-CT scanning at 1-week and 4-week interval.

2.6. Statistical Analyses. The data were analyzed by SPSS software 19.0 (SPSS Science, SPSS Inc., Chicago, IL, USA). Statistical differences of mineral density and lesion depth between groups were evaluated by one-way ANOVA at $\alpha=$ 0.05 .

\section{Results}

3.1. SEM Images and EDX Analysis. The SEM images and EDX analysis at 1 week are shown in Figures 1 and 2.

The dentinal tubules remained open with a diameter of $3 \sim 5 \mu \mathrm{m}$ in the artificial dentin caries (Figure 1(a)). Dense and orderly hexagonal crystal structure could be observed on the dentin surface of Group FHA and they covered the dentinal tubules and dentin surface (Figure 1(b)). Average diameter of the hexagonal crystal was about $1 \mu \mathrm{m}$ (Figure $2(\mathrm{a})$ ) and the thickness was about 4 5 $\mu \mathrm{m}$ (Figure 2(b)), which exhibited elemental peaks for calcium, phosphorus, carbon, and oxygen.

In Group $\mathrm{CH}$, the dentinal tubules were partially occluded with crystal, which exhibited elemental peaks for calcium, carbon, oxygen, and barium. In Group MTA, the dentinal tubules were also occluded with cement phase, which exhibited elemental peaks for calcium, magnesium, silicon, carbon, and oxygen.

The SEM images at 4 weeks were similar to those at 1 week (data not shown).

3.2. XRD and FT-IR Spectroscopy. The XRD diffractogram and FT-IR spectra for all test materials are shown in Figure 3. The hexagonal crystal constructed by FHA gel also exhibited characteristic peaks of hydroxyapatite (HA) and fluorapatite (FA) (Figure 3(a1)), of which the spectrograph was nearly the same as that of natural dentin [16].

The crystal of Group $\mathrm{CH}$ exhibited characteristic peaks of calcium hydroxide $\left(\mathrm{Ca}(\mathrm{OH})_{2}\right)$ and barium sulfate $\left(\mathrm{BaSO}_{4}\right)$ (Figure 3(b1)), while that of Group MTA exhibited characteristic peaks of bismuth oxide $\left(\mathrm{Bi}_{2} \mathrm{O}_{3}\right)$, tricalcium silicate $\left(3 \mathrm{CaO} \cdot \mathrm{SiO}_{2}\right)$, dicalcium silicate $\left(2 \mathrm{CaO} \cdot \mathrm{SiO}_{2}\right)$, calcium carbonate $\left(\mathrm{CaCO}_{3}\right)$, and calcium dialuminate $\left(3 \mathrm{CaO} \cdot \mathrm{Al}_{2} \mathrm{O}_{3}\right)$ (Figure 3(c1)) [17].

FT-IR spectra showed the bands or functional groups of the powders. The spectra of the hexagonal crystal were similar to those of natural dentin (Figure 3(a2)). A broad peak indicated $3800-2600 \mathrm{~cm}^{-1}$ and a small peak between $3536 \mathrm{~cm}^{-1}$ and $3545 \mathrm{~cm}^{-1}$ was related to the $\mathrm{OH}^{-}$. A sharp and broad peak between $1100 \mathrm{~cm}^{-1}$ and $900 \mathrm{~cm}^{-1}$ was related to the $\mathrm{PO}_{4}{ }^{3-}$ group. Stretching and bending modes for $\mathrm{PO}_{4}{ }^{3-}$ were shown at $600 \mathrm{~cm}^{-1}$ and $572-560 \mathrm{~cm}^{-1}$. Bands of $1500-$ $1400 \mathrm{~cm}^{-1}$ were related to the $\mathrm{CO}_{3}{ }^{2-}$ group [16].

As for $\mathrm{Ca}(\mathrm{OH})_{2}$, a broad peak indicated $3800-2600 \mathrm{~cm}^{-1}$ and a sharp peak between $3700 \mathrm{~cm}^{-1}$ and $3600 \mathrm{~cm}^{-1}$ was related to the $\mathrm{OH}^{-}$. Bands of $1500-1400 \mathrm{~cm}^{-1}$ were related to the $\mathrm{C}-\mathrm{O}$ group. A sharp and broad peak between $1210 \mathrm{~cm}^{-1}$ and $1040 \mathrm{~cm}^{-1}$ and at $610 \mathrm{~cm}^{-1}$ was related to the $\mathrm{SO}_{4}{ }^{2-}$ group (Figure 3(b2)) [18].

As the spectra of MTA showed, the splitting of the band in the $1000-850 \mathrm{~cm}^{-1}$ region resulted from the presence of silicate phases. The bands in the $1600-1300 \mathrm{~cm}^{-1}$ corresponded to the asymmetric stretching of the $\mathrm{CO}_{3}{ }^{2-}$ group. A broad peak indicated $3800-2600 \mathrm{~cm}^{-1}$ and a small peak between $3536 \mathrm{~cm}^{-1}$ and $3545 \mathrm{~cm}^{-1}$ was related to the $\mathrm{OH}^{-}$ (Figure 3(c2)) [19].

3.3. Micro-CT Scanning. Development of DMD at each lesion level was presented in Figure 4. There were no significant differences in the baseline $(0 \mathrm{~W})$ DMD and lesion depth between groups $(P>0.05)$. Figure 4 presented an artificial caries lesion with a depth of approximately $300 \sim 400 \mu \mathrm{m}$ and a surface DMD of $1.73 \mathrm{~g} / \mathrm{cm}^{3}$.

After the IPT for $1 \mathrm{~W}$, the DMD of dentin surface layer in the group FHA significantly increased to $2.018 \pm 0.041 \mathrm{~g} / \mathrm{cm}^{3}$ because of the hexagonal crystal $(P<0.05$, Figures 5(b1) and 5(b2)), and the density was $1.756 \pm 0.044 \mathrm{~g} / \mathrm{cm}^{3}$ in the control group, $1.775 \pm 0.038 \mathrm{~g} / \mathrm{cm}^{3}$ in Group $\mathrm{CH}$, and $1.796 \pm 0.008 \mathrm{~g} / \mathrm{cm}^{3}$ in Group MTA. However, there were no significant changes in the mineral density of the subsurface part of the lesion, nor in the lesion depth (Figure 4(a)).

After the IPT for $4 \mathrm{~W}$, the DMD of dentin surface layer in Group FHA significantly increased to $2.077 \pm 0.012 \mathrm{~g} / \mathrm{cm}^{3}$ compared to the baseline at $0 \mathrm{~W}(P<0.05$, Figures $5(\mathrm{cl})$ and 5(c2)), but there was no significant difference with the $\mathrm{DMD}$ at $1 \mathrm{~W}(P>0.05)$. The DMD of dentin surface layer was $1.764 \pm 0.045 \mathrm{~g} / \mathrm{cm}^{3}$ in the control group, $1.775 \pm 0.009 \mathrm{~g} / \mathrm{cm}^{3}$ in Group $\mathrm{CH}$, and $1.805 \pm 0.135 \mathrm{~g} / \mathrm{cm}^{3}$ in Group MTA. There were still no significant changes in the mineral density of the subsurface part of the lesion, nor in the lesion depth (Figure 4(b)).

Micro-CT images showed that the hexagonal crystal covered nearly all the surface of dentinal caries lesions after being capped with FHA gel for 1 week and 4 weeks (Figures 5(b1) and 5(c1)). The crystal constructed on the surface and the mineral density of the surface layer increased, while the mineral density of the subsurface part of the lesion as well as lesion depth presented similar results as those before the IPT (Figures 5(b2) and 5(c2)).

\section{Discussion}

The present study was designed to assess the remineralizing efficacy of FHA gel system on artificial dentin caries lesions. Dental apatite is multiphase and can be described as carbonate-substituted or fluor-substituted hydroxyapatite [20]. This gel system contained $\mathrm{Ca}^{2+}, \mathrm{PO}_{4}{ }^{3-}, \mathrm{OH}^{-}$, and all ionic components that were necessary during HA crystal construction. Commercial product $\mathrm{Ca}(\mathrm{OH})_{2}$ in the present study was comprised of $\mathrm{Ca}(\mathrm{OH})_{2}$ and $\mathrm{BaSO}_{4}$ which is used as a developer, and the main components of MTA were calcium silicate. FHA gel system embodied a distinct advantage when compared with $\mathrm{Ca}(\mathrm{OH})_{2}$ and MTA, which could not provide the phosphate ion needed during remineralization. 


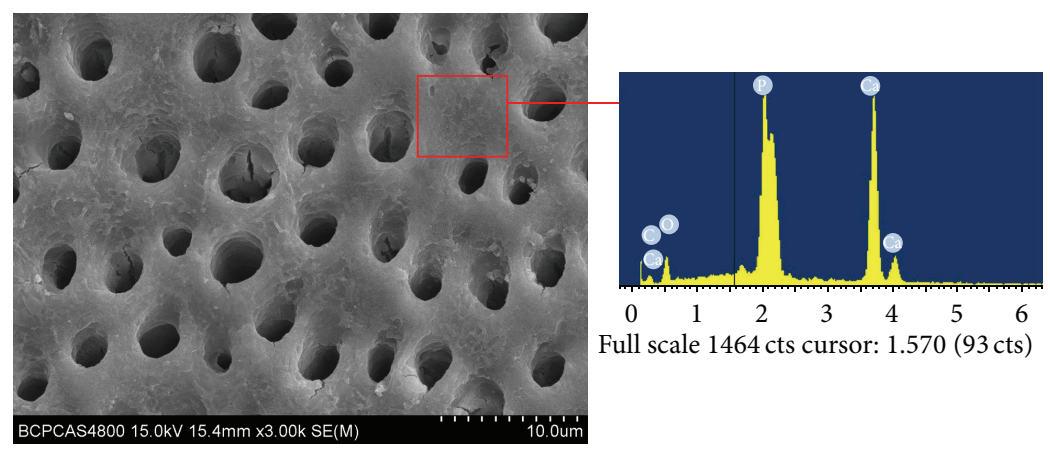

(a)
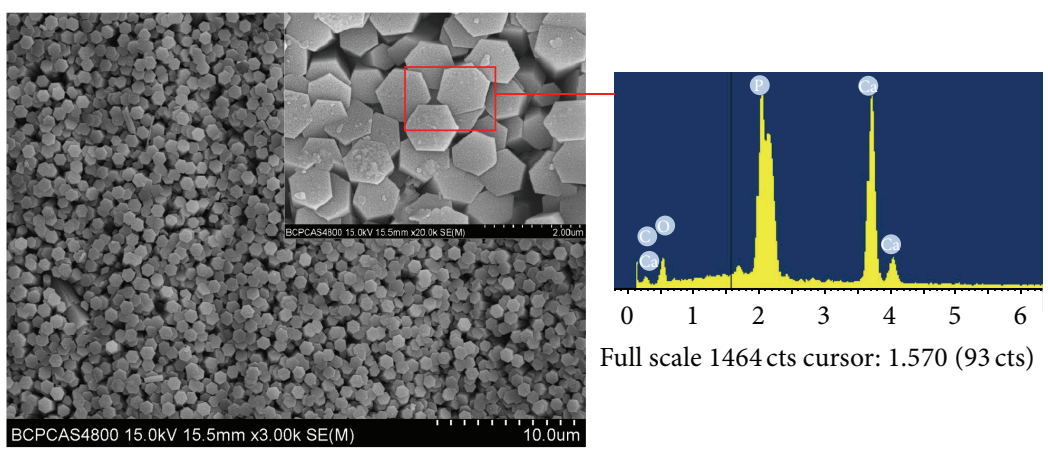

Full scale 1464 cts cursor: 1.570 (93 cts)

(b)

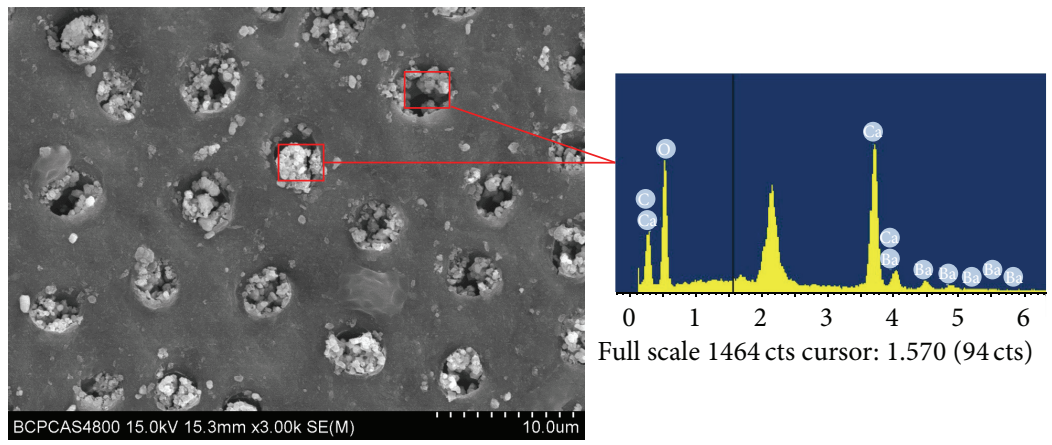

(c)
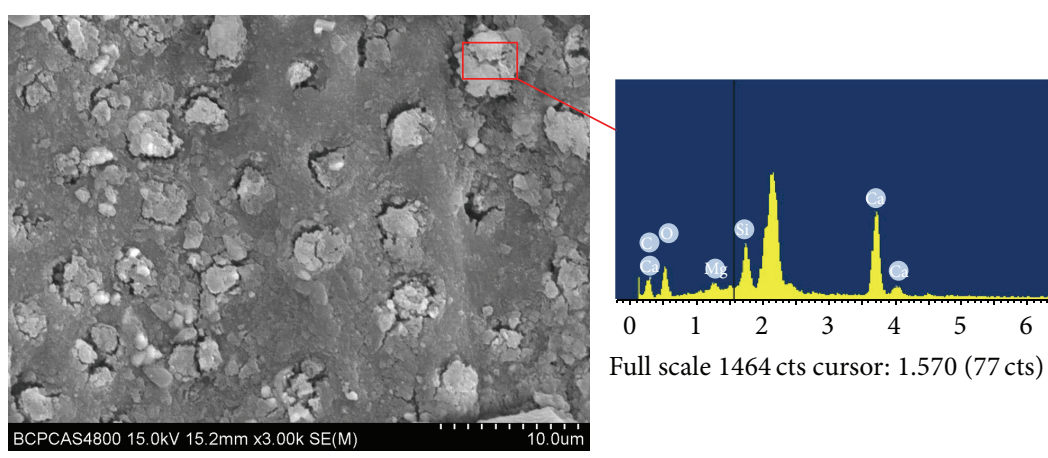

Full scale 1464 cts cursor: 1.570 ( 77 cts)

(d)

FIGURE 1: SEM images and EDX analysis of artificial caries layer surface. (a) Artificial dentin caries, (b) Group FHA, hexagonal crystal structure on artificial caries layer, exhibited elemental peaks for $\mathrm{Ca}$ P, C, and O, (c) Group CH, artificial caries layer with crystal in dentin tube, exhibited elemental peaks for $\mathrm{Ca}, \mathrm{C}, \mathrm{O}$, and Ba, and (d) Group MTA, artificial caries layer with crystal in dentin tube, exhibited elemental peaks for Ca, $\mathrm{Si}, \mathrm{Mg}, \mathrm{C}$, and $\mathrm{O}$. 


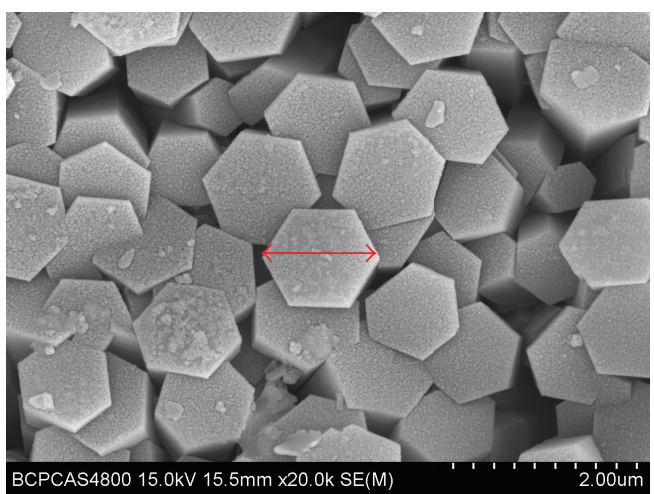

(a)

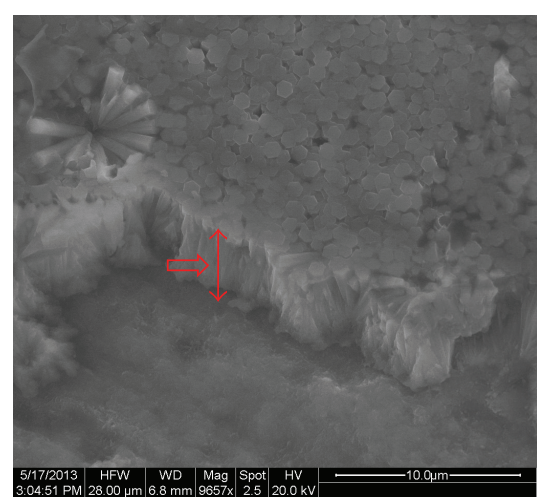

(b)

FIGURE 2: SEM image for the hexagonal crystal on the artificial caries surface of Group FHA. (a) The diameter of the hexagonal crystal was about $1 \mu \mathrm{m}$. (b) The thickness of the hexagonal crystal was about $4 \sim 5 \mu \mathrm{m}$.

Another innovation was the application of agarose in this system. Recently, biomimetic mineralization approaches with an organic matrix to control apatite growth and orientation have been shown to induce enamel or dentin regeneration [21, 22]. Ning et al. obtained disordered deposited hydroxyapatite on dentin surface using agarose gel loaded with calcium phosphate. They also suggested that agarose hydrogel may provide the hydrogel microenvironment to mimic dentin formation and agarose may be considered as a template to control mineralization. We also used agarose in FHA gel system in the present study and obtained preferred orientation hydroxyapatite/fluorapatite crystals on dentin surface, and agarose may play the same role of hydrogel microenvironment and template based on the same mechanism as in previous report. The anionic groups of agarose in its monomeric units may bond to collagen molecules that carry a positive charge and induce HA crystals to nucleate and grow [22].

A unidirectional ion supply is thought to play a critical role in apatite growth and orientation [23]. In FHA gel system, calcium ions and phosphate ions may undergo oriented diffusion in the agarose hydrogel toward the dentin surface, which supplies ionic fluid from one direction as the source of mineralization [24].

A hypothetical model for the process may be summarized as follows. The formation of FA crystals is determined by two processes: the initiation of nucleation and the continued growth of nucleate [14]. It was believed that, in the initial stage, crystal nuclei form spontaneously in supersaturated solutions, and ions attach around the crystal nuclei. Agarose molecules in FHA gel system bond to the collagen molecules with positive charge on the dentin surface and formed the nucleation site. Calcium ions and phosphate ions in FHA gel diffuse to the site where mineralization occurs. Atomic or molecular building blocks will find the energetically favorable sites and integrate into the surface of the immature crystal. Nucleation clusters are generated in random orientation and then spontaneously aggregate into primary nanoparticles to minimize the total surface energy. Because van der Waals attraction along the long axis of the rods is stronger than that at the rod ends, rod-like crystals form a bundle when continuing their growth. When the surface is covered with crystals, larger crystals would huddle together and maintain a uniform direction. In addition, the gel system provides a hydrogel microenvironment and the agarose may act as a template to induce nucleation and growth [22].

The layer of hexagonal crystal cannot be removed using an ultrasonic cleaner, which suggests that there may be some physical and chemical structures at the junction of crystal and dentin substrate surface. The results showed that the layer covered nearly all dentinal tubules and dentin surface, which may decrease permeation of demineralized dentin and protect the function of the pulp-dentinal complex.

In addition, this system also contained fluoride, which, in a remineralizing system, can be preferentially incorporated in the new mineral "veneer." The absorbed fluoride on partially demineralized crystal surfaces enhances mineral reprecipitation, leading to the formation of a new surface on the existing crystal remnants with lower solubility $[25,26]$.

The mineral density and lesion depth of artificial dentin caries were measured by the micro-CT system, which is a nondestructive technique [27]. After being capped with FHA gel for $1 \mathrm{~W}$ and $4 \mathrm{~W}$, the DMD of dentin surface layer in Group FHA significantly increased, which was probably due to the dense layer of hexagonal crystal in Group FHA.

There were no significant changes in the mineral density of the subsurface part of the lesion, nor in the lesion depth in all three groups. The explanation may be that the apatite was too large to enter the space between collagen fibers. This is also the limitation and problem identified with other remineralizing systems [28]. Li and Chang found that when calcium phosphate nuclei grew to microspheres with a diameter of about $1 \mu \mathrm{m}$ and interconnected by collagen nanofibers, the apatite could just locate on the collagen fibers of surface layer [28]. Furthermore, the mineral content of surface layer affects the characteristics of subsequent remineralization [29]. Although fluorapatite enhances mineral uptake, it causes hypermineralization of the lesion surface and prevents effective remineralization of deeper parts of the caries lesion $[29,30]$. 


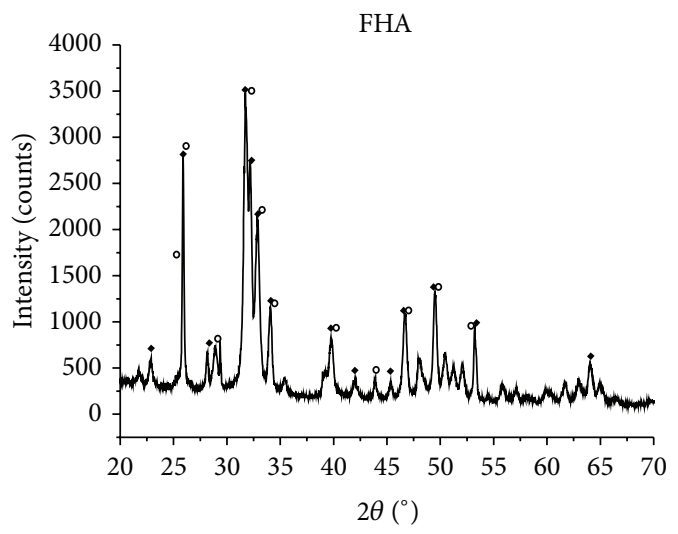

- HA

- FA

(a1)

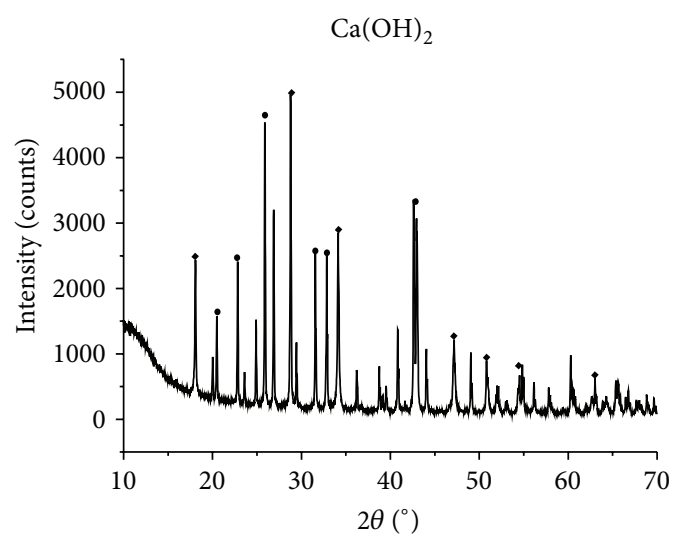

- $\mathrm{Ca}(\mathrm{OH})_{2}$

- $\mathrm{BaSO}_{4}$

(b1)

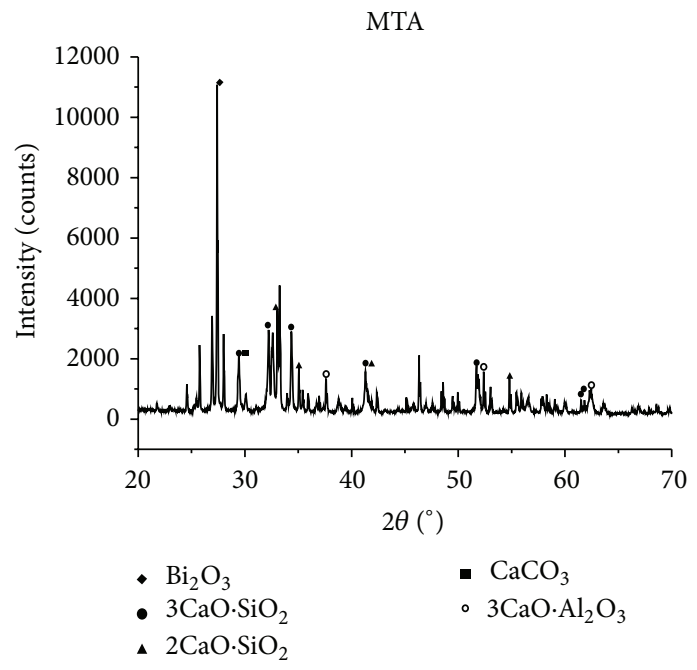

(c1)

- $3 \mathrm{CaO} \cdot \mathrm{SiO}_{2}$

- $3 \mathrm{CaO} \cdot \mathrm{Al}_{2} \mathrm{O}_{3}$
FHA

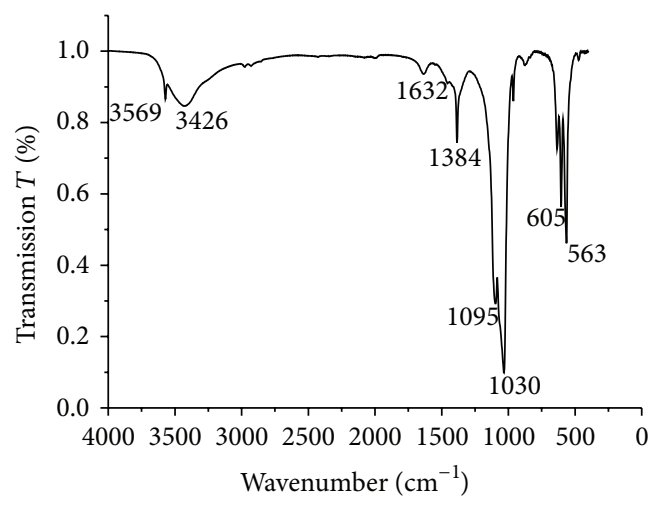

(a2)

$\mathrm{Ca}(\mathrm{OH})_{2}$

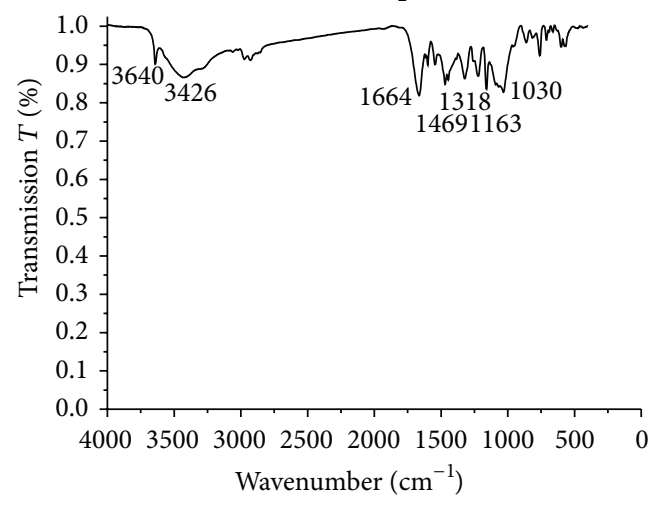

(b2)

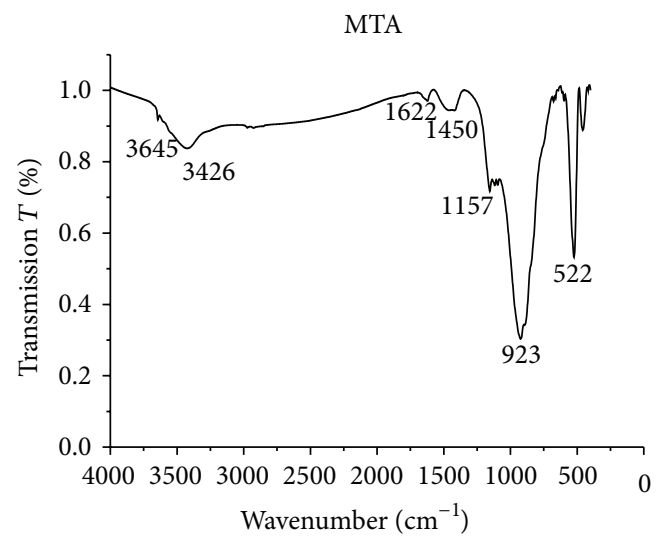

(c2)

FIGURE 3: XRD spectrograph (a1, b1, and c1) and FT-IR (a2, b2, and c2) spectra of the hexagonal crystal of Group FHA, Ca(OH) 2 , and MTA. (al and a2) Group FHA; (b1 and b2) Group CH; (cl and c2) Group MTA. 


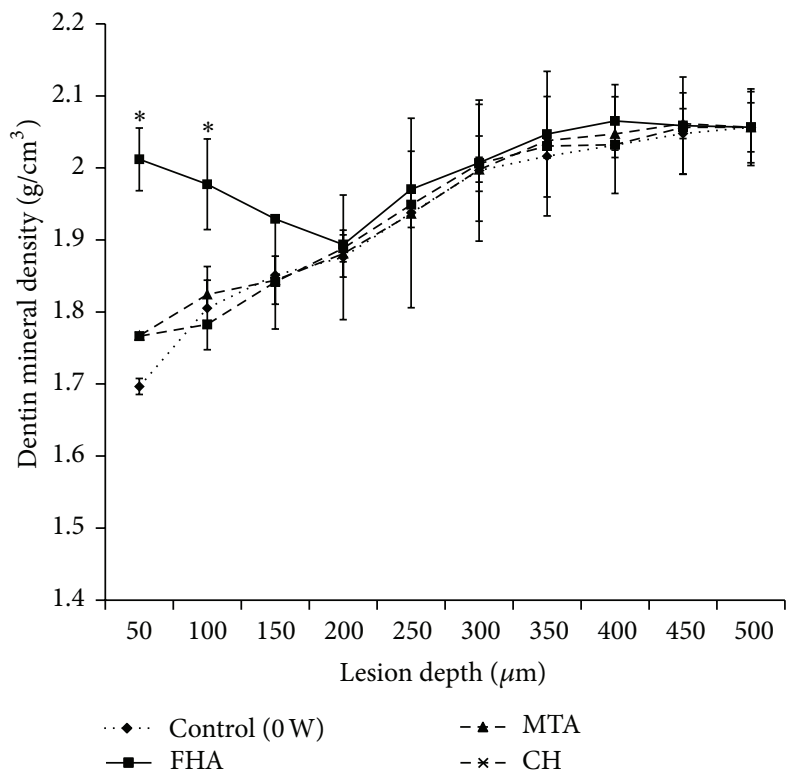

(a)

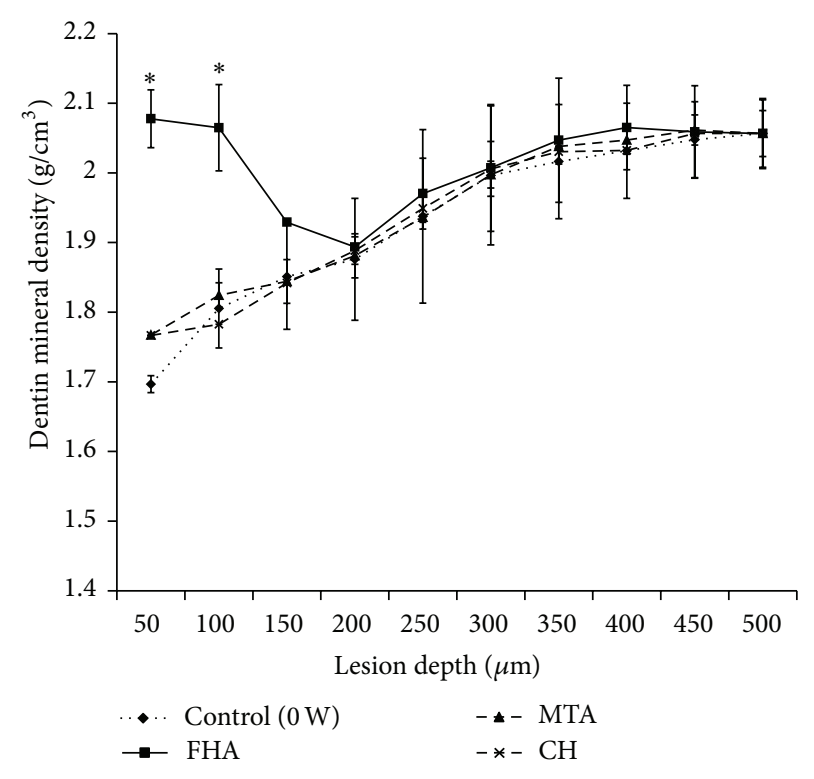

(b)

Figure 4: Dentin mineral density (DMD) and lesion depth of dentin disks after being treated for 1 week (a) and 4 weeks (b). Values represent the mean $\pm \operatorname{SD}\left(n=6,{ }^{*} P<0.05\right)$.

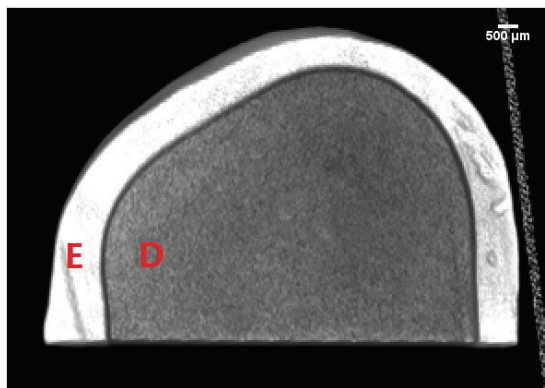

(a1)

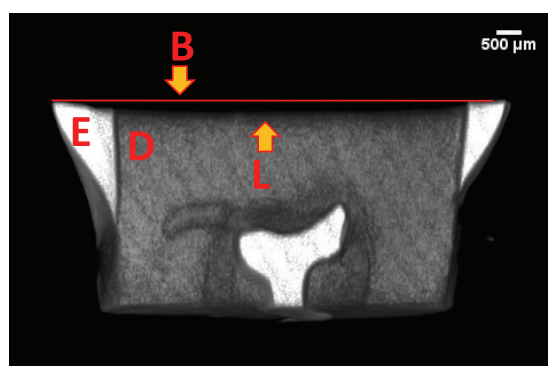

(a2)

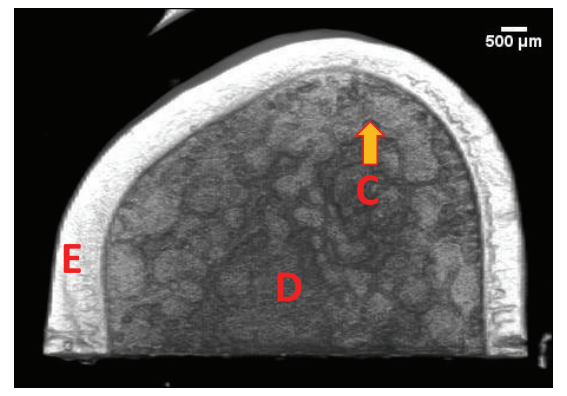

(b1)

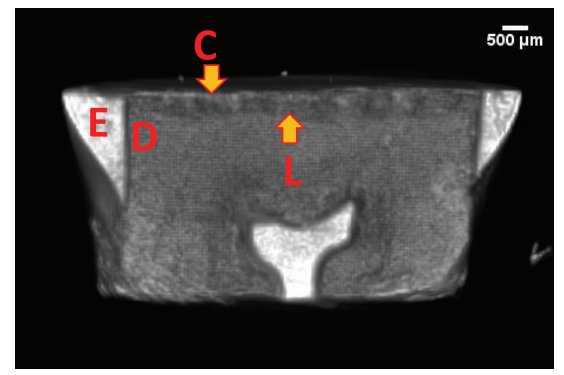

(b2)

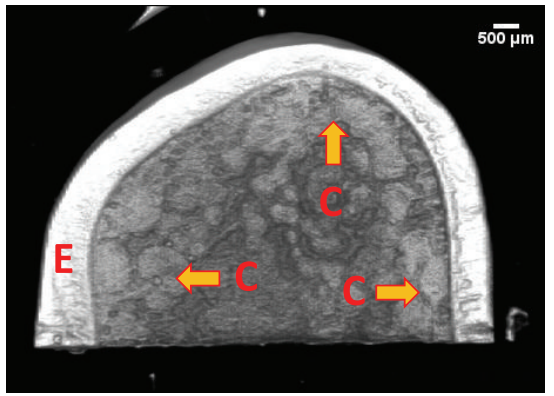

(c1)

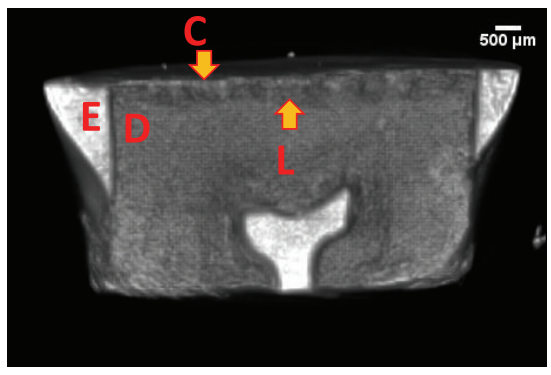

(c2)

FIGURE 5: Micro-CT images of artificial dentinal caries lesion before (a1 and a2) and after being capped with FHA gel for 1 week (b1 and b2) and 4 weeks ( $\mathrm{cl}$ and $\mathrm{c} 2$ ). Hexagonal crystal covered nearly all the surface of the dentin (b1 and $\mathrm{cl}$ ), and the mineral density of surface layer significantly increased (b2 and c2). E, enamel; D, dentin; C, crystal; L, lesion.

Amorphous calcium phosphate (ACP) is known as an important intermediate phase in the formation of calcium phosphate [24,31]. Recently, a strategy called "Guided Tissue Remineralization" represents an approach to this problem by attempting to backfill the demineralized dentin collagen with liquid-like ACP nanoprecursor particles that are stabilized by biomimetic analogs of noncollagenous proteins [12]. This strategy manages to achieve the goal of biomineralization 
of caries-like dentin [32, 33]. Taken into account, the incorporation of biomimetic analogs of matrix proteins may be an effective solution in future studies.

\section{Conclusion}

In the present study, the administration of FHA gel resulted in a well-compacted fluorapatite layer deposited onto the dentin surface and significant increase of the mineral density. These findings suggest that FHA gel might be a proper IPT material with remineralizing function.

\section{Conflict of Interests}

The authors declare that there is no conflict of interests regarding the publication of this paper.

\section{Acknowledgments}

This project is supported by the National Basic Research Program of China (2012CB933900), the Key International S\&T Cooperation Projects (2011DFA32190), the Key Technologies R\&D Program of China (2012BAI07B01), and the Science Foundation of Peking University School and Hospital of Stomatology (PKUSS20130103).

\section{References}

[1] D. Ericson, E. Kidd, D. McComb, I. Mjör, and M. J. Noack, "Minimally Invasive Dentistry-concepts and techniques in cariology," Oral Health \& Preventive Dentistry, vol. 1, no. 1, pp. 59-72, 2003.

[2] H. Miyauchi, M. Iwaku, and T. Fusayama, "Physiological recalcification of carious dentin," Bulletin of the Tokyo Medical and Dental University, vol. 25, no. 3, pp. 169-179, 1978.

[3] D. Ericson, "What is minimally invasive dentistry?" Oral Health \& Preventive Dentistry, vol. 2, supplement 1, pp. 287-292, 2004.

[4] E. Bresciani, W. C. Wagner, M. F. L. Navarro, S. H. Dickens, and M. C. Peters, "In vivo dentin microhardness beneath a calciumphosphate cement," Journal of Dental Research, vol. 89, no. 8, pp. 836-841, 2010.

[5] C. Estrela and R. Holland, "Calcium hydroxide: study based on scientific evidences," Journal of Applied Oral Science, vol. 11, no. 4, pp. 269-282, 2003.

[6] Q. Shen, J. Sun, J. Wu, C. Liu, and F. Chen, "An in vitro investigation of the mechanical-chemical and biological properties of calcium phosphate/calcium silicate/bismutite cement for dental pulp capping," Journal of Biomedical Materials Research Part B: Applied Biomaterials, vol. 94, no. 1, pp. 141-148, 2010.

[7] C. F. Cox and S. Suzuki, "Re-evaluating pulp protection: calcium hydroxide liners vs. cohesive hybridization," The Journal of the American Dental Association, vol. 125, no. 7, pp. 823-831, 1994.

[8] M. Aeinehchi, B. Eslami, M. Ghanbariha, and A. S. Saffar, "Mineral trioxide aggregate (MTA) and calcium hydroxide as pulp-capping agents in human teeth: a preliminary report," International Endodontic Journal, vol. 36, no. 3, pp. 225-231, 2003.
[9] M. Torabinejad and M. Parirokh, "Mineral trioxide aggregate: a comprehensive literature review-part II: leakage and biocompatibility investigations," Journal of Endodontics, vol. 36, no. 2, pp. 190-202, 2010.

[10] M. Parirokh and M. Torabinejad, "Mineral trioxide aggregate: a comprehensive literature review-Part I: chemical, physical, and antibacterial properties," Journal of Endodontics, vol. 36, no. 1, pp. 16-27, 2010.

[11] M. Parirokh and M. Torabinejad, "Mineral trioxide aggregate: a comprehensive literature review-part III: clinical applications, drawbacks, and mechanism of action," Journal of Endodontics, vol. 36, no. 3, pp. 400-413, 2010.

[12] F. R. Tay, D. H. Pashley, F. A. Rueggeberg, R. J. Loushine, and R. N. Weller, "Calcium phosphate phase transformation produced by the interaction of the portland cement component of white mineral trioxide aggregate with a phosphate-containing fluid," Journal of Endodontics, vol. 33, no. 11, pp. 1347-1351, 2007.

[13] Y.-P. Qi, N. Li, L.-N. Niu et al., "Remineralization of artificial dentinal caries lesions by biomimetically modified mineral trioxide aggregate," Acta Biomaterialia, vol. 8, no. 2, pp. 836842, 2012.

[14] S. Liu, Y. Yin, and H. Chen, "PEO-assisted precipitation of human enamel-like fluorapatite films for tooth whitening," CrystEngComm, vol. 15, no. 29, pp. 5853-5859, 2013.

[15] J. M. McIntyre, J. D. B. Featherstone, and J. Fu, "Studies of dental root surface caries. 1: comparison of natural and artificial root caries lesions," Australian Dental Journal, vol. 45, no. 1, pp. 2430, 2000.

[16] N. Montazeri, R. Jahandideh, and E. Biazar, "Synthesis of fluorapatite-hydroxyapatite nanoparticles and toxicity investigations," International Journal of Nanomedicine, vol. 6, pp. 197201, 2011.

[17] I. A. Belío-Reyes, L. Bucio, and E. Cruz-Chavez, "Phase composition of ProRoot mineral trioxide aggregate by X-ray powder diffraction," Journal of Endodontics, vol. 35, no. 6, pp. 875-878, 2009.

[18] M. Saitoh, S. Masutani, T. Kojima, M. Saigoh, H. Hirose, and M. Nishiyama, "Thermal properties of dental materials-cavity liner and pulp capping agent," Dental Materials Journal, vol. 23, no. 3, pp. 399-405, 2004.

[19] L. Grech, B. Mallia, and J. Camilleri, "Characterization of set intermediate restorative material, biodentine, bioaggregate and a prototype calcium silicate cement for use as root-end filling materials," International Endodontic Journal, vol. 46, no. 7, pp. 632-641, 2013.

[20] W. Zhao, S. Wang, H. Hong, Z. Chen, M. Fan, and S. Yu, “The crystallographic properties of the mineral phases of enamel and dentin in normal deciduous and permanent teeth," Zhonghua Kou Qiang Yi Xue Za Zhi, vol. 37, no. 3, pp. 219-221, 2002.

[21] M. Iijima and J. Moradian-Oldak, "Control of apatite crystal growth in a fluoride containing amelogenin-rich matrix," Biomaterials, vol. 26, no. 13, pp. 1595-1603, 2005.

[22] T.-Y. Ning, X.-H. Xu, L.-F. Zhu et al., "Biomimetic mineralization of dentin induced by agarose gel loaded with calcium phosphate," Journal of Biomedical Materials Research Part B: Applied Biomaterials, vol. 100, no. 1, pp. 138-144, 2012.

[23] M. Iijima, K. Hayashi, and Y. Moriwaki, "Effects of the $\mathrm{Ca}^{2+}$ and $\mathrm{PO}_{4}^{3-}$ ion flow on the lengthwise growth of octacalcium phosphate in a model system of enamel crystal formation with controlled ionic diffusion," Journal of Crystal Growth, vol. 234, no. 2-3, pp. 539-544, 2002. 
[24] L. B. Gower, "Biomimetic model systems for investigating the amorphous precursor pathway and its role in biomineralization," Chemical Reviews, vol. 108, no. 11, pp. 4551-4627, 2008.

[25] J. D. B. Featherstone, "Dental caries: a dynamic disease process," Australian Dental Journal, vol. 53, no. 3, pp. 286-291, 2008.

[26] I. Diamanti, H. Koletsi-Kounari, E. Mamai-Homata, and G. Vougiouklakis, "Effect of fluoride and of calcium sodium phosphosilicate toothpastes on pre-softened dentin demineralization and remineralization in vitro," Journal of Dentistry, vol. 38, no. 8, pp. 671-677, 2010.

[27] S. K. Manesh, C. L. Darling, and D. Fried, "Assessment of dentin remineralization with PS-OCT," in Lasers in Dentistry $X V$, vol. 7162 of Proceedings of SPIE, Society of Photo-Optical Instrumentation Engineers, February 2009.

[28] X. Li and J. Chang, "Preparation of bone-like apatite-collagen nanocomposites by a biomimetic process with phosphorylated collagen," Journal of Biomedical Materials Research-Part A, vol. 85, no. 2, pp. 293-300, 2008.

[29] K. Kawasaki, J. Ruben, H. Tsuda, M. C. D. N. J. M. Huysmans, and O. Takagi, "Relationship between mineral distributions in dentine lesions and subsequent remineralization in vitro," Caries Research, vol. 34, no. 5, pp. 395-403, 2000.

[30] K. P. Preston, P. W. Smith, and S. M. Higham, "The influence of varying fluoride concentrations on in vitro remineralisation of artificial dentinal lesions with differing lesion morphologies," Archives of Oral Biology, vol. 53, no. 1, pp. 20-26, 2008.

[31] H. Cölfen, "Single crystals with complex form via amorphous precursors," Angewandte Chemie International Edition, vol. 47, no. 13, pp. 2351-2353, 2008.

[32] Y. Liu, S. Mai, N. Li et al., "Differences between top-down and bottom-up approaches in mineralizing thick, partially demineralized collagen scaffolds," Acta Biomaterialia, vol. 7, no. 4, pp. 1742-1751, 2011.

[33] A. K. Burwell, T. Thula-Mata, L. B. Gower et al., "Functional remineralization of dentin lesions using polymer-induced liquid-precursor process," PLoS ONE, vol. 7, Article ID e38852, 2012. 

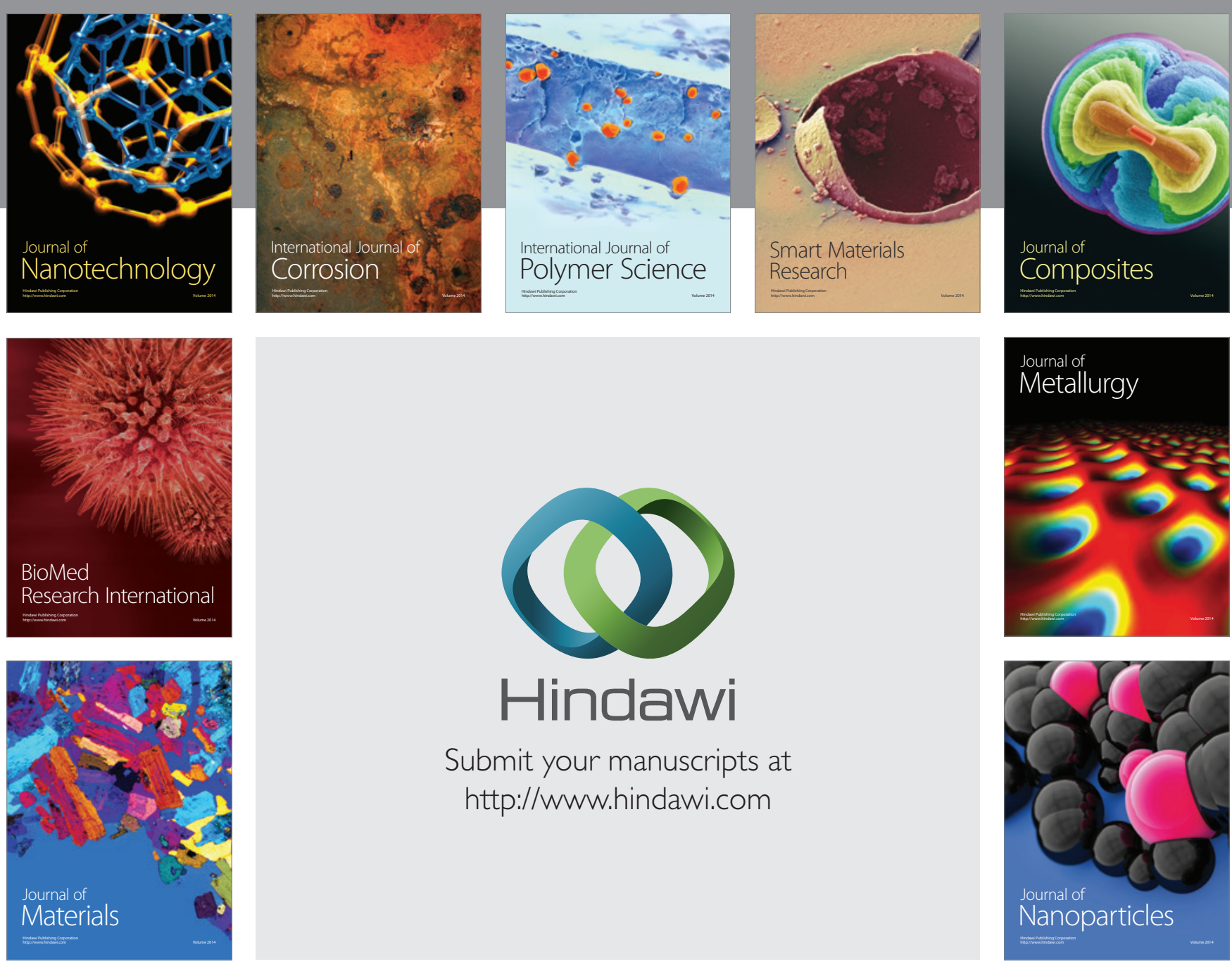

Submit your manuscripts at http://www.hindawi.com
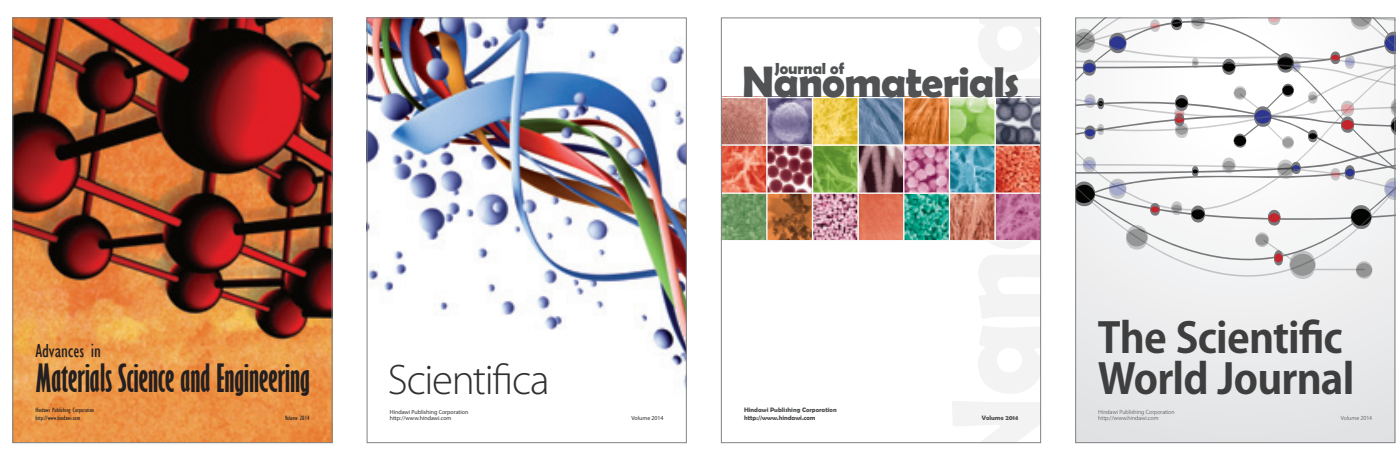

\section{The Scientific World Journal}
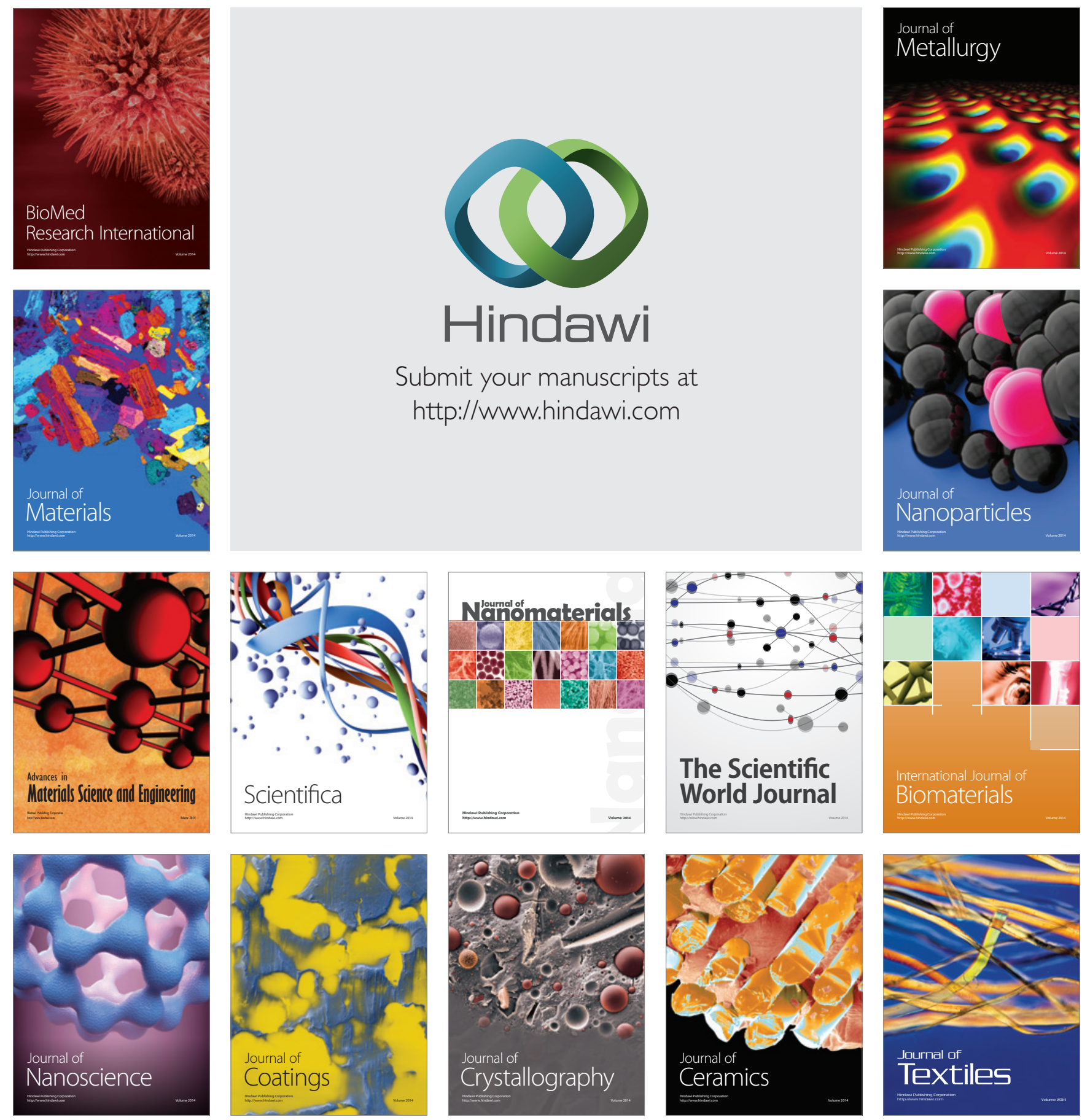